\title{
Definition of a Possible Genetic Basis for Susceptibility to Acute Myelogenous Leukemia Associated with the Presence of a Polymorphic la Epitope
}

\author{
Stephanie Seremetis, Janet Cuttner, and Robert Winchester \\ Erwin S. and Rose F. Wolfson Laboratory of Cellular Mechanisms of Disease, Hospital for Joint Diseases, New York, New York 10003
}

\begin{abstract}
The polymorphic Ia epitope recognized by monoclonal antibody $109 \mathrm{~d} 6$ is detectable on the leukemic cells of a significantly increased number of individuals with acute myelogenous leukemia, compared with its frequency in normal healthy control individuals. In control individuals, the presence of the $109 \mathrm{~d} 6$ epitope is closely correlated with but not identical to the DRw53 allospecificity. However, the frequency of particular conventional Ia allodeterminants, including DRw53, is not significantly elevated in the leukemia group. Considerable evidence supports the conclusion that the high frequency of the $109 \mathrm{~d} 6$ epitope reflects an inherited basis for susceptibility to the development of acute myelogenous leukemia and not a differentiation event occurring in the leukemic lineage. The 109d6 determinant is expressed by leukemic myeloblasts as well as by homologous normal B cells and monocytes obtained from the same individuals during remission of the leukemia. Furthermore, in healthy family members the 109d6 epitope is encoded by Ia haplotypes that are shared with the patient. Of special interest, certain of these haplotypes have combinations of the 109d6 epitope and Ia specificities not commonly seen in normal individuals; here, also, healthy family members share these haplotypes.
\end{abstract}

\section{Introduction}

The acute myelogenous leukemias (1) exhibit certain features in common, including an origin from a putative stem cell committed to granulocyte-monocyte differentiation (2), frequent nonrandom chromosomal alterations (3), and the presence of characteristic cell membrane maturational and differentiation antigens (4-7). The latter include the expression of Ia antigens on both acute myelogenous leukemia cells $(5,6,9)$ as well as on normal bone marrow cells at analogous stages of differentiation (6) and a variety of other monocyte-granulocyte lineage antigens (7, 10-14). The variable expression of certain of these antigens, along with morphologic and cytoenzymatic criteria, defines the relative position of the leukemic cells from different individuals in the maturational sequence of the early stages of differentiation in the myeloid-monocytoid lineages $(1,4,7$, 10-14).

The recognition that the murine leukemia induced by the Gross virus is under control of genes mapping in the major

Dr. Cuttner's address is The Polly Annenberg Levee Division of Hematology, Department of Medicine, Mount Sinai School of Medicine, New York, NY.

Received for publication 28 February 1985.

J. Clin. Invest.

(C) The American Society for Clinical Investigation, Inc.

0021-9738/85/10/1391/07 \$1.00

Volume 76, October 1985, 1391-1397 histocompatibility complex $(\mathrm{MHC})^{1}(15)$ has nurtured continued interest in the human MHC and its relationship to leukemogenesis. Most studies of HLA associations with myeloid leukemias have been restricted to HLA A and B loci or to the HLA DR locus and no strong associations between these loci and leukemia have been found (16-18). However, D'Amaro et al. (19) recently reported an association of the $\mathrm{C}$ locus allele Cw4 with acute myelogenous leukemia in patients who had achieved remission and undergone bone marrow transplantation.

The human Ia antigens are class II MHC products of the HLA-D region composed of two transmembrane polypeptides: an $\alpha$-chain of $34,000 \mathrm{D}$ and a $\beta$-chain of $29,000 \mathrm{D}$. Recently, there have been considerable advances in understanding the genetic organization of the Ia system through the techniques of gene cloning and monoclonal antibodies. Both chains of the Ia molecules are encoded by genes found in three subregions: $D R$, DQ (DC or DS), and DP (SB) (20). Two polymorphic $\beta$-chain sequences and one nonpolymorphic $\alpha$-chain are thought to be encoded in the DR subregion, while the more centromeric DQ subregion contains two pairs of polymorphic $\alpha$-chain and $\beta$ chain genes; the DP subregion is similarly organized (21-25).

Monoclonal anti-Ia antibodies have been of considerable use in delineating the complexity of the Ia system because their homogeneity makes it possible to identify specific epitopes, particularly those that are polymorphic. Moreover, because monoclonal antibodies are derived from heteroimmunizations, it is possible that they might recognize certain structures on the Ia molecule that are not targets for alloimmune response. For example, antibody $109 \mathrm{~d} 6$ reacts with an epitope expressed on a single $\beta$-chain (26) that in the normal population is closely correlated with, but molecularly distinct from, the occurrence of both the allospecificity DRw53 (MT3) (27) and an epitope recognized by the monoclonal antibody 17-3-3S (28). Another antibody, IDV 12, is directed to a determinant on the $\beta$-chain of DQ molecules that is most closely correlated with the allospecificity DQw3 (MB3) $(27,29,30)$. The epitope recognized by antibody IVD1 2 has been found at significantly increased frequency in individuals with chronic lymphocytic leukemia (29). This suggested that the study of other hematopoietic neoplasms with monoclonal antibodies specific for polymorphic la epitopes might reveal MHC disease associations not apparent from studies using only alloantisera.

The present study of the Ia system in acute myelogenous leukemia is an investigation of the hypothesis that certain Ia epitopes recognized by monoclonal antibodies are important in myeloid leukemogenesis, providing a novel approach to the possible genetic basis of this disease. A preliminary report of this work has been presented (31).

1. Abbreviations used in this paper: $\mathrm{AML}$, acute myelogenous leukemia; FAB, French-American-British; MHC, major histocompatibility complex; RR, relative risk; TdT, terminal deoxyribonucleotidyl transferase. 


\section{Methods}

Patients. 77 individuals with acute myelogenous leukemia were distributed among French-American-British (FAB) classification M1-M6 (1) and terminal deoxyribonucleotidyl transferase (TdT) ${ }^{+} \mathrm{AML}$, a newly defined subgroup (32). Six were $M 1,20$ were $M 2$, four were $M 3,21$ were M4, four were M5, four were M6, and 18 were classified as $\mathrm{TdT}^{+} \mathrm{AML}$. All were studied between November 1982 and November 1984, and came from the Mount Sinai Medical Center and affiliated institutions. The leukemias of these individuals were classified as myelogenous on the basis of conventional cytochemical analysis (33-35) and cell surface phenotype was defined by a panel of monoclonal antibodies specific for myelomonocytic differentiation antigens $(10,11,14)$. The $\mathrm{TdT}^{+} \mathrm{AML}$ subgroup was composed of leukemias that would have been classified as typical FAB M1-M6 leukemias by conventional criteria (1), but which expressed the nuclear enzyme TdT (32). TdT was analyzed according to the product literature of the Bethesda Research Laboratories (Bethesda, MD) (36). Where available, mononuclear cells at the time of remission and relapse were studied, as were cells from family members. As disease controls, 44 individuals with chronic lymphocytic leukemia, 14 patients with chronic myelogenous leukemia, and 18 patients with acute lymphocytic leukemia were studied over the same time period. The healthy control population was ethnically matched and studied during the same time period with the same reagents. The frequency of all determinants in this subpopulation was not significantly different from that of a larger control population, $n=129$, studied at different times.

Cells. Enriched preparations of blast cells depleted of mature granulocytes were isolated by Ficoll (Pharmacia Fine Chemicals, Piscataway, NJ)-Hypaque (Winthrop Laboratories, New York, NY) centrifugation (37) and, where necessary, further enrichment was obtained by Percoll (Pharmacia Fine Chemicals) discontinuous density gradient centrifugation (38). Enrichment resulted in $>70 \%$ blasts in all specimens studied. Cell separation of remission blood specimens was performed by FicollHypaque centrifugation and $\mathrm{E}^{-}$cells were isolated by the standard rosetting technique using neuraminidase treated sheep erythrocytes (39). Lymphoblastoid cell lines were derived from remission blood samples using Epstein-Barr virus containing supernatants of the mycoplasma free cell line B95-8 according to established procedures (40).

Sufficient cells from most individuals were typed for Ia alloantigens by the standard National Institutes of Health microcytotoxicity assay with 7th, 8th, and 9th International Histocompatibility workshop reagents as well as with locally available sera $(29,40,41)$. On occasional instances in which control negative antisera gave reactions greater than a cytotoxicity score of one, the microcytotoxicity data was not included for analysis. Statistical analyses were performed using the Haldane formulation of the relative risk, the population attributable risk, and the one-tailed Fisher exact probability calculation, as previously described $(29,42)$. In this study, the frequently employed correction for random associations was not used because of the inability to rigorously specify the number of distinct reagents because of haplotypic associations between the determinants detected by certain reagents. However, even if it is adversely assumed that all specificities tested for are unassociated, the level of observed significance of the association with the presence of $109 \mathrm{~d} 6 \mathrm{de}-$ terminant would only change from $P<0.000005$ to $P<0.0005$.

Monoclonal antibodies. Monoclonal antibody $109 \mathrm{~d} 6$ is an anti-human Ia reagent generated by immunizing BALB/c mice with hairy cell leukemia cells from a DR4/5+ individual. The antibody recognizes a polymorphic la determinant associated with, but not identical to, DRw53, DR4, and DR7 in studies of normal control individuals $(27,28)$. Monoclonal antibody 17-3-3S is an anti-murine Ia reagent specific for an I-E allodeterminant that also recognizes a polymorphic human Ia determinant most closely associated with that recognized by antibody $109 \mathrm{~d} 6$ and the DRw53 specificity $(28,43)$. Similarly, a lower order of association exists with the DR4 or DR7 allotypes $(27,28)$. The determinants recognized by antibody 109d6 and antibody $17-3-3 S$ are correlated in the population, but are borne on distinct molecules (28). Monoclonal antibody IVD1 2 is directed against a polymorphic determinant on la molecules associated with the DQw3 allospecificity and with $r=0.820$ for the presence of DR4 or DR5 $(29,30)$. SG171A is a monomorphic antiIa monoclonal antibody (44) detecting determinants common to DR and DQ molecules. Cells producing antibody $109 \mathrm{~d} 6$ were provided by Dr. G. Burmester, of the Erwin S. and Rose F. Wolfson Laboratory of Cellular Mechanisms of Disease, Hospital for Joint Diseases, New York, NY; those producing IVD12 were provided by Dr. C. Hurley and Dr. D. Capra, University of Texas; 17-3-3S was supplied by Dr. David Sachs of the National Institutes of Health; and SG171A, by Dr. Sanna Goyert, of the Erwin S. and Rose F. Wolfson Laboratory of Cellular Mechanisms of Disease. The isotypes of 109d6, 17-3-3S, IVD12, and SG171 are IgG2a, $\operatorname{IgG} 2 \mathrm{a}, \operatorname{IgG} 1$, and IgG2a, respectively.

Immunofluorescence. The indirect microstaining method with saturating quantities of antibodies was employed as previously described $(22,38)$. In brief, after IgG Fc receptors were blocked with aggregated human $\mathrm{Ig}, 0.010 \mathrm{ml}$ of $1 \mathrm{mg} / \mathrm{ml}, 1 \times 10^{5}$ cells were incubated with saturating quantities of monoclonal antibodies $(0.05 \mathrm{ml}$ of undiluted supernatants containing $30-40 \mu \mathrm{g} / \mathrm{ml}$ of antibody) at $4^{\circ} \mathrm{C}$ for $30 \mathrm{~min}$ in a V-bottom microtiter plate (Cook Laboratories, Alexandria, VA). After four washings with phosphate-buffered saline, $\mathrm{pH} 7.2$, containing $1 \%$ bovine serum albumin and $0.01 \% \mathrm{NaN}_{3}, \mathrm{~F}\left(\mathrm{ab}^{\prime}\right)_{2}$ fragments of goat antimouse IgG conjugated with tetramethyl rhodamine isothiocyanate or fluorescein isothiocyanate were added to each well. After a 30-min incubation at $4^{\circ} \mathrm{C}$, the cells were washed four times and analyzed by flow cytometry on a fluorescence activated cell sorter (FACS IV, Becton Dickinson, Oxnard, CA), using a microsampler system. The narrow angle forward scatter signal was used to gate out dead cells. The fluorescence histograms of 20,000-50,000 cells were acquired using logarithmic preamplification. These cells were also examined using incident illumination in a fluorescence microscope (Leitz, Wetzlar, West Germany). Irrelevant monoclonal antibodies of the same isotypes were used as negative controls.

\section{Results}

Reactivity with polyclonal anti-Ia alloantisera in microcytotoxicity. Using conventional anti-Ia alloantisera, the leukemic blasts of 49 individuals with acute myelogenous leukemia were found to have a profile of DR types similar to those found on cells of an appropriate normal control population (Table I). Assignment of any particular DR type was not significantly associated with acute myelogenous leukemia at the 0.05 level using uncorrected exact probability calculations. Similarly, the DQw1, DRw52, and DRw53 allospecificities were not significantly associated with the occurrence of leukemia although the frequency of the latter specificity was slightly increased.

Reactivity with monoclonal antibodies directed to polymorphic Ia determinants. As shown in Table I, the monoclonal antibody $109 \mathrm{~d} 6$ reacted with an epitope expressed on the blasts found in $85 \%$ of 77 acute myelogenous leukemia patients but only in $40.5 \%$ of controls, relative risk $(R R)=+7.88$, population attributable risk $(\delta)=0.75, P<0.000005$ (uncorrected). In a healthy caucasian control population, the molecule bearing the $109 \mathrm{~d} 6$ determinant is usually found in association with the HLA DRw53 allospecificity determined by polyclonal typing reagents, $r=0.724$ (20), but in the leukemic group the frequency of HLA DRw53 was slightly, but not significantly, increased. In the control Caucasian population, the presence of the 17-3-3S determinant is associated with the presence of the $109 \mathrm{~d} 6$ determinant, $r=0.783$. However, reactivity of leukemic blasts with the monoclonal antibody $17-3-3 \mathrm{~S}$ was found in only $48 \%$ of patients and in $39 \%$ of control $\mathrm{E}^{-}$cells, a nonsignificant difference. In the leukemia group, the $109 \mathrm{~d} 6$ and the 17-3-3S determinants were not highly correlated; $r=0.4323$. In contrast, reactivity of the leukemic blasts with monoclonal antibody IVD12 was only 
Table I. Polymorphic Epitope Recognized by Monoclonal Antibody 109d6 Is Strongly Associated with the Occurrence of Acute Myelogenous Leukemia

\begin{tabular}{|c|c|c|c|}
\hline \multirow[b]{2}{*}{ Ia specificity } & \multicolumn{2}{|c|}{ Frequency (percent) } & \multirow[b]{2}{*}{ Haldane relative risk } \\
\hline & $\begin{array}{l}\text { Acute } \\
\text { myelogenous } \\
\text { leukemia }\end{array}$ & $\begin{array}{l}\text { Matched } \\
\text { normal } \\
\text { control }\end{array}$ & \\
\hline & $n=49$ & $n=48$ & \\
\hline DR1 & 30 & 20 & 1.65 \\
\hline DR2 & 16 & 29 & -2.05 \\
\hline DR3 & 26 & 13 & 2.42 \\
\hline DR4 & 38 & 23 & 2.09 \\
\hline DR5 & 34 & 38 & -1.13 \\
\hline DRw6 & 4 & 14 & -3.43 \\
\hline DR7 & 24 & 20 & 1.21 \\
\hline DRw8 & 6 & 2 & 2.39 \\
\hline DRw9 & 0 & 0 & 0 \\
\hline DRw10 & 0 & 2 & -3.126 \\
\hline DQw1 & 40 & 57 & -1.84 \\
\hline DRw52 & 66 & 65 & 1.00 \\
\hline DRw53 & 50 & 38 & 1.65 \\
\hline 17-3-3S (MoAb) & $48^{*}$ & 39 & 1.44 \\
\hline IVD12 (MoAb) & $16^{*}$ & 46 & $-4.49(P<0.00027)$ \\
\hline 109d6 (MoAb) & $85^{*}$ & 42 & $7.88(P<0.000005)$ \\
\hline
\end{tabular}

* For 109d6, 17-3-3S, and IVD12, $n=77$.

found in $16 \%$ of patients compared with $46 \%$ in the control population. There was no statistically significant association of any pattern of antibody reactivity with a specific FAB subset classification of the acute myelogenous leukemias to the exclusion of other categories.

Studies of other hematopoietic neoplasms. During the period of this study using the same reagents, a series of other hospitalized patients with various hematopoietic neoplasms were studied as controls. The frequencies of $109 \mathrm{~d} 6$ observed on either leukemic or residual normal cells or both were as follows: among 44 patients with chronic lymphocytic leukemia, $48 \%$; among 15 patients with chronic myelogenous leukemia, $41 \%$ (including seven that had a predominance of blasts in stages of maturity equivalent to those of the acute myelogenous leukemic blasts). The frequency of $109 \mathrm{~d} 6$ reactivity in 18 patients with acute lymphocytic leukemia was $44 \%$. In none of these populations were these frequencies significantly different from that of $109 \mathrm{~d} 6$ expression observed in the control population.

Monoclonal antibody 109d6 reactivity: population studies. Individuals with AML differed in part from normal controls with respect to polymorphic la antigen phenotypes usually correlated with the presence of the 109d6 epitope (Table II). While $59 \%$ of leukemic individuals expressing the 109d6 epitope had a phenotype that included the expected specificities HLA DRw53 and either DR4 or DR7, unusual combinations of polymorphic Ia determinants were found in $34 \%$ of the patients, and in $6 \%$ of normal control individuals $(\mathrm{RR}=7.00, P<0.0005)$. Of particular interest, the presence of the $109 \mathrm{~d} 6$ epitope in the phenotype $109 \mathrm{d6}^{+} 17-3-3 \mathrm{~S}^{-}$DRw53- was found in $14 \%$ of those with leukemia but in only $2 \%$ of the control population (RR $=5.59, P<0.03)$. Similarly, the $109 \mathrm{~d}^{+} 17-3-3 \mathrm{~S}^{+} \mathrm{DRw} 53^{-}$phenotype was identified in $20 \%$ of leukemic patients and $4 \%$ of controls ( $R R=4.95, P<0.01$ ). Only $14 \%$ of individuals with leukemia lacked any of the Ia antigens summarized in Table II (RR $=-7.8, P<0.000005)$.

Haplotype assignment of genes encoding the 109d6 epitope. Fig. 1 illustrates an informative family in which the unusual $109 \mathrm{~d} 6^{+} 17-3-3 \mathrm{~S}^{-}$DRw53- phenotype was present. The gene encoding the $109 \mathrm{~d} 6$ epitope was assigned to the $C$ haplotype, and no evidence was found in the family members for the presence of genes encoding the 17-3-3S or DRw53 determinants on this haplotype. The $\mathrm{C}$ haplotype coding for the molecules bearing the 109d6 epitope contained genes that coded for the specificities DR1 and DQw1. This haplotype was found in two healthy siblings. In three other families, not illustrated, the gene encoding the 109d6 determinant was assigned to the haplotypes bearing

Table II. Certain Patterns of Reactivity with Monoclonal Anti-Ia Antibodies in Acute Myelogenous Leukemia Cells Are Not Those Predicted by Expected Associations with DR Specificities Found in Controls

\begin{tabular}{|c|c|c|c|c|c|c|c|}
\hline \multicolumn{2}{|c|}{$\begin{array}{l}\text { Percentage of individuals with } \\
\text { phenotype }\end{array}$} & \multicolumn{5}{|c|}{ Ia antigen phenotype } & \multirow[b]{2}{*}{ Relative risk } \\
\hline Leukemia & Controls & DR4 & DR7 & DRw53 & $17-3-3 S$ & $109 \mathrm{~d} 6^{*}$ & \\
\hline$n=49$ & $n=48$ & & & & & & \\
\hline 20 & 4 & - & - & - & + & + & $+4.95(P<0.01 \ddagger)$ \\
\hline 14 & 2 & - & - & - & - & + & $+5.59(P<0.03 \ddagger)$ \\
\hline 0 & 4 & - & - & + & - & + & -5.32 \\
\hline 8 & 2 & + & - & + & - & + & +3.13 \\
\hline 18 & 13 & + & - & + & + & + & +1.53 \\
\hline 12 & 17 & - & + & + & + & + & -1.41 \\
\hline 4 & 0 & + & + & + & - & + & 5.1 \\
\hline 8 & 0 & + & + & + & + & + & 9.5 \\
\hline 14 & 58 & - & - & - & - & - & $-7.88(P<0.000005)$ \\
\hline
\end{tabular}

\footnotetext{
* Note: In acute myelogenous leukemia individuals where both microcytotoxicity and immunofluorescence data were available $(n=40), 109 \mathrm{~d} 6$ was positive in $86 \%$. In those acute myelogenous leukemia individuals where only immunofluorescence data were available $(n=77), 109 \mathrm{~d} 6$ was positive in $85 \%$. ¥ For the phenotype $109 \mathrm{d6}^{+}$DRw53- (not considering reactivity with antibody $17-3-3 S$ ) the frequencies are: leukemia, 34\%; controls, $6 \%(\mathrm{RR}=7.00, P<0.0005)$.
} 




Figure 1. Family study illustrating inheritance of genes encoding the $109 \mathrm{~d} 6$ antigenic determinant in association with DR1. Assignment of genes encoding the determinants to haplotypes is illustrated in the lower part of the figure. Only the propositus and siblings sharing the "c" haplotype express 109d6, and therefore 109d6 is assigned to this haplotype that carries DRI and DQw1 as well.

* The parents were typed by inference.

either DR4 or DR7 genes, and in each instance was associated with the presence of the genes encoding the DRw53 specificity and the 17-3-3S Ia determinant. In each of the families studied, the proband was heterozygous for the $109 \mathrm{~d} 6$ epitope, which was clearly associated with a single haplotype within the family.

Remission blood studies. The possibility that expression of the determinant recognized by antibody $109 \mathrm{~d} 6$ was an event unique to the leukemic lineage was further explored by determining the presence of molecules bearing the 109d6 epitope on the blood mononuclear cells of individuals in which leukemic remissions had been induced. Table III shows that in six indi- viduals the reactivity of remission B cells with the $109 \mathrm{~d} 6$ and 17-3-3S antibodies was similar to that observed for the homologous leukemic blasts. In two of these individuals (T.Z. and D.E.) both the leukemic blasts and remission $\mathrm{E}^{-}$cells were of the unusual phenotype $109 \mathrm{d6}^{+}, 17-3-3 \mathrm{~S}^{-}$, DRw53-.

Fig. 2 illustrates the similarity of the patterns of Ia antigen expression on leukemic blasts and remission $\mathrm{E}^{-}$mononuclear cells obtained from the same individual with the leukemic blast cell phenotype of $109 \mathrm{~d}^{+}, 17-3-3 \mathrm{~S}^{-}, \mathrm{DRw} 53^{-}$. The epitope with which antibody $109 \mathrm{~d} 6$ reacts is present on both the leukemic and the remission mononuclear cells. A B cell lymphoblastoid line derived from this individual had a phenotype identical to that of the $\mathrm{E}^{-}$remission blood cells and the leukemic blasts by HLA and monoclonal antibody typing (data not shown).

Monoclonal antibody IVD12. The diminished frequency of reactivity to monoclonal antibody IVD12 on leukemic blasts (Tables I and IV) was also not as predicted by associations observed, primarily due to the disproportionately low frequency of reactivity with $\mathrm{DR}^{+}$or $\mathrm{DR}^{+}$individuals, who would be predicted to express this determinant. In contrast, in control individuals, the assignment of DR4 or DR5 was closely correlated with expression on blood mononuclear cells of molecules recognized by the IVD12 antibody, as expected.

In a family where the DR4 $4^{+} \mathrm{DRw} 53^{+}$IVD $12^{+}$haplotype was found in one parent and two healthy siblings, the leukemic cells of the proband also expressed the allospecificities DR4 DRw53, but $<1 \%$ of blasts expressed the IVD12 epitope as measured by flow cytometry performed at a gain of 16 as well as by conventional immunofluorescence microscopy. However, here the leukemic blasts strongly expressed both $109 \mathrm{~d} 6$ determinants, and control monomorphic la determinants detected by antibody SG171A.
Table III. Similarity of Expression of 109d6 Epitopes on Leukemic Blast and Homologous Remission $E^{-}$Mononuclear Cells

\begin{tabular}{|c|c|c|c|c|c|}
\hline \multirow[b]{2}{*}{ Individual } & \multirow[b]{2}{*}{ Cells } & \multirow{2}{*}{$\begin{array}{l}\text { Micro-cytotoxicity } \\
\text { DR type }\end{array}$} & \multicolumn{3}{|c|}{$\begin{array}{l}\text { Reactivity with } \\
\text { monoclonal antibody }\end{array}$} \\
\hline & & & IVD12 & $17-3-3 S$ & $109 \mathrm{~d} 6$ \\
\hline \multirow[t]{2}{*}{ T.Z. } & Leukemic blasts & $1,3, w 52$ & - & - & + \\
\hline & Remission $\mathrm{E}^{-}$cells & $1,3, w 52$ & - & - & + \\
\hline \multirow[t]{2}{*}{ L.A. } & Leukemic blasts & $3,7, w 52, w 53$ & - & - & + \\
\hline & Remission $\mathrm{E}^{-}$cells & $3,7, w 52, w 53$ & - & - & + \\
\hline \multirow[t]{2}{*}{ P.E. } & Leukemic blasts & $4,7,-, w 53$ & - & + & + \\
\hline & Remission $\mathrm{E}^{-}$cells & $4,7,-, 3, w 53$ & + & + & + \\
\hline \multirow[t]{2}{*}{ M.A. } & Leukemic blasts & $4,-, 3,2, w 52, w 53$ & - & - & + \\
\hline & Remission $\mathrm{E}^{-}$cells & $4,-, 3,2, w 52, w 53$ & + & - & + \\
\hline (Relapse) & Leukemic blasts & $4,-, 3,2, w 52, w 53$ & - & - & + \\
\hline \multirow[t]{2}{*}{ D.O. } & Leukemic blasts & $4,7,-, w 53$ & - & + & + \\
\hline & Remission $\mathrm{E}^{-}$cells & $4,7,-, w 53$ & + & + & + \\
\hline \multirow[t]{2}{*}{ D.E. } & Leukemic blasts & $5, w 6,-, w 52$ & - & - & + \\
\hline & Remission $\mathrm{E}^{-}$cells & $5, w 6,-, w 52$ & + & - & + \\
\hline
\end{tabular}

${ }^{+}$Indicates immunofluorescent staining by the antibody on $>90 \%$ of cells bearing Ia antigens. - Indicates staining on $<1 \%$ of cells bearing Ia antigens.

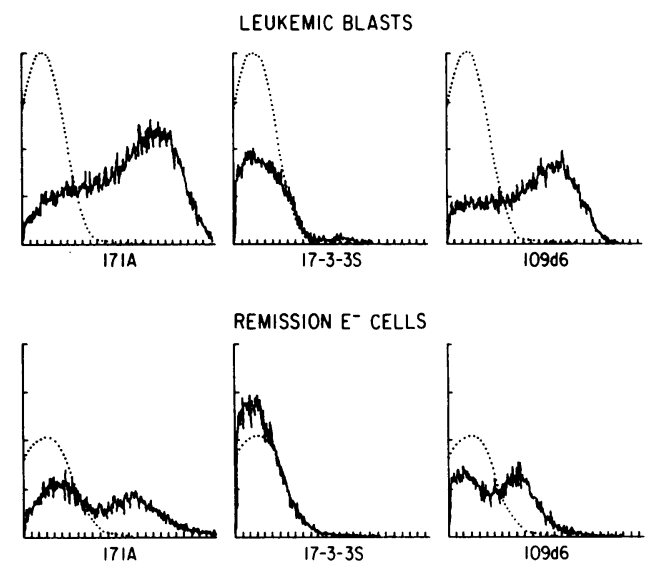

Figure 2. Comparison of the immunofluorescence distribution histograms of per cell la antigen expression between leukemic blasts and an $\mathrm{E}^{-}$lymphocyte preparation from blood obtained after remission was induced. The ordinate is cell number and the abscissa is log fluorescence over 3.4 decades. Approximately half of the remission $\mathrm{E}^{-}$cells express Ia antigens detected by antibody $109 \mathrm{~d} 6$ and $171 \mathrm{~A}$, while staining by antibody 17-3-3S is indistinguishable from the control. The leukemic blasts strongly expressed $171 \mathrm{~A}$ and $109 \mathrm{~d} 6$ determinants, and were devoid of reactivity with antibody 17-3-3S. DR typing of the remission cells by microcytotoxicity revealed DR1 DR3 DRw52 DQ1. In each histogram the control reactivity $(\cdots)$ is the immunofluorescence profile obtained with a monoclonal antibody of the same isotype but of irrelevant specificity. 
Table IV. Epitope Recognized by Monoclonal Antibody IVD12 Is Not Expressed on Leukemic Myeloblasts as Predicted by Expected Associations with DR Specificities in Controls

\begin{tabular}{|c|c|c|c|c|c|}
\hline \multicolumn{2}{|c|}{$\begin{array}{l}\text { Percentage of individuals } \\
\text { with phenotype }\end{array}$} & \multirow[b]{2}{*}{ DR4 } & \multirow[b]{2}{*}{ DR5 } & \multirow[b]{2}{*}{ IVD12 } & \multirow{2}{*}{$\begin{array}{l}\text { Fisher } \\
P \text { value }\end{array}$} \\
\hline Leukemic & Control & & & & \\
\hline$n=48$ & $n=49$ & & & & \\
\hline 30 & 2 & + & - & - & 0.00016 \\
\hline 22 & 6 & - & + & - & 0.02 \\
\hline
\end{tabular}

Studies of three additional individuals whose blasts and remission B cells typed as DR4 and one individual whose blasts and remission cells typed as DR5 revealed that in all four there was no detectable reactivity by immunofluorescence with antibody IVD12 on leukemic blasts, but typical strong positive staining was detected on remission blood B cells and monocytes (Table III). In each, the leukemic blasts and the remission blood cells were readily stained by antibody $109 \mathrm{~d} 6$ as well as by antibody SG171A.

\section{Discussion}

The central observation of this study is that a polymorphic Ia epitope detected by the monoclonal antibody 109d6 is identified in a significantly increased number of individuals with acute myelogenous leukemia. Various lines of evidence support the interpretation that genetic events are responsible for this finding. In family studies the genes encoding the 109d6 epitope were assigned to haplotypes that segregated in both normal and leukemic individuals. The family and remission studies were consistent in both $109 \mathrm{d6}^{+} \mathrm{DRw} 53^{+}$and $109 \mathrm{d6}^{+}$DRw53- leukemic propositi. In addition, the 109d6 epitope was found to be expressed on both the leukemic myeloblasts and on the normal B cells and monocytes obtained from blood of individuals in remission. These results argue strongly against the possibility that anomalous leukemia-related differentiation events are responsible for the unusual frequency of expression of the $109 \mathrm{~d} 6$ epitope.

Particular attention was directed to the possibility that technical factors such as interaction with the Fc receptors of the leukemic cells were responsible for the reactivity with antibody 109d6. However, no evidence in favor of this possibility was obtained. In data not shown, staining with a variety of isotype matched irrelevant antibodies was negative ( $<1.0 \%$ of cells) under the conditions used to avoid Fc receptor interactions. Moreover, antibody $109 \mathrm{~d} 6$ did not react with the mature granulocytes of 20 healthy individuals, nor was it identified on an increased frequency of early granulocytoid forms from individuals with chronic myelogenous leukemia even when their blood contained abundant blasts of a stage of maturity equivalent to those found in the acute myelogenous leukemia groups.

In contrast, the decreased expression of a different polymorphic epitope recognized by antibody IVD1 2 was found to be controlled by events occurring within the leukemic lineage. Here, normal B cells and monocytes obtained from remission blood samples had the IVD12 epitope, while the leukemic cells from the same individuals lacked detectable IVD12 epitopes.
These findings are consistent with the observation by Navarette et al. (46) that MT1 (DQ1) is found less frequently among those with acute myelogenous leukemia, and provide another example of the noncoordinate expression of the Ia gene products, which has also been observed in hematopoietic precursors (47), acute lymphoblastic leukemic blasts (48), some cell lines (49), and normal blood monocytes $(50,51)$. Using two newly available monoclonal antibodies specific for determinants only expressed on DQ molecules, essentially no staining of these leukemic blasts was found in 12 individuals. To the extent that certain acute myelomonocytic and monoblastic leukemias represent clonal expansions of blood monocyte precursors, the absence of detectable DQ on all studied leukemias is of interest because at later stages in monocyte differentiation DQ molecules are expressed $(50,51)$.

Monoclonal antibodies offer distinct advantages in the search for molecular structures that relate to disease susceptibility and the function of the Ia molecules. The monoclonal reagents have inherent precision not attainable in complex polyclonal alloantisera because they are not composed of indeterminant mixtures of antibodies directed to various allodeterminants. Secondly, the monoclonal antibodies potentially identify certain polymorphic determinants that are not necessarily allelic markers because the trans-species immunization potentially leads to the recognition of unusual and genetically interesting epitopes. Accordingly, the use of monoclonal antibodies allows a search for the function of variant forms of la molecules to be pursued at the level of the epitopes on the Ia molecule that are most likely to subserve particular functions (43).

An important principle underlying this study is the delineation of a disease association that is primarily found with an epitope of the la molecule detected by a monoclonal antibody rather than with a marker necessarily associated with alternative allelic, gene forms. The absence of a consistent association in the leukemia patients with any defined DR allospecificity including that of DRw53 (MT3) in this series emphasizes this point since in normal individuals the $109 \mathrm{~d} 6$ epitope is closely correlated with the allodeterminant DRw53 (27-29). In this respect, of greater significance is the equivalent lack of significant association in the acute myelogenous leukemia group with the epitope defined by antibody 17-3-3S, which in normal individuals is closely correlated with the presence of the $109 \mathrm{~d} 6$ epitope, and, in turn, with the DRw53 specificity. In the leukemia groups, the 17-3-3S epitope correlated with DRw53 but not with the presence of the 109d6 epitope. Along with the finding of the unusual haplotypes containing genes coding for the $109 \mathrm{~d} 6$ epitope, these data are best explained by assuming that the $109 \mathrm{~d} 6$ epitope is borne on an Ia molecule that is not uniformly associated with the presence of the DRw53 specificity. Moreover, available biochemical and immunologic evidence obtained in reference cell lines from healthy individuals reveals that one variety of $2 \mathrm{D}$ gel pattern is given by molecules bearing the $109 \mathrm{~d} 6$ epitope in the setting of DRw53 containing haplotypes, while a second pattern is found when the $109 \mathrm{~d} 6$ epitope is found in association with non-DRw53 haplotypes such as that expressed with DR1 (Matsuyama, T., J. Silver, and R. Winchester, manuscript in preparation). Moreover, restriction fragment length polymorphisms in the DNA from normal DRw53 ${ }^{+} 109 \mathrm{~d} 6^{+}$individuals are different from those observed in DRw53- $109 \mathrm{d6}^{+}$individuals (Paulsen, G., E. Qvigstad, G. Gaidernack, L. Rask, R. Winchester, and E. Thorsby, manuscript submitted for publication). This raises the possibility that in normal individuals different 
varieties of DR or Ia molecules encoded at different DR $\beta$ loci bear the $109 \mathrm{~d} 6$ determinants. Until the biochemical basis of the $109 \mathrm{~d} 6$ epitope is defined in the special situation of the unusual Ia phenotypes associated with acute myelogenous leukemia, we must consider the possibility that different types of DR molecules bear the 109d6 epitope in different individuals.

An association of the $\mathrm{C}$ locus allele $\mathrm{Cw} 4$ with the acute leukemias, including acute myelogenous leukemia, was recently reported (19). $35 \%$ of North American patients bore this marker with a relative risk of 2.06 . The study group consisted of selected patients who had already attained remission and had undergone bone marrow transplantation. The possibility was raised that the $\mathrm{Cw} 4$ association could be interpreted as evidence for either primary leukemic susceptibility or alternatively for regulating processes pertinent to response to chemotherapy (19). Of further importance, no significant association between chronic myelogenous leukemia and any HLA locus was found (19). The present study was not primarily directed to an analysis of HLA A, B, and $C$ antigens; however, among 14 patients the frequency of Cw4 was $21 \%$, not significantly different from the frequency of $20 \%$ observed in the control group. Although no such association is apparent in these 14 patients, analysis of a larger number might reveal a linkage disequilibrium between the $\mathrm{Cw} 4$ allele and genes encoding the $109 \mathrm{~d} 6$ determinant.

While the significance of the presence of Ia gene products on normal hematopoietic progenitor cells is not certain, it has been suggested that they might be involved in cell-cell recognition events important to the regulation of proliferation and differentiation within the bone marrow rather than functioning as classic immune response gene products (6). In this way the $109 \mathrm{~d} 6$ determinant or the molecule bearing it could endow a myeloid cell with altered responsiveness to certain as yet undefined hematopoietic regulatory influences. Alternatively, the $109 \mathrm{~d} 6 \mathrm{de}-$ terminant could serve as the specific receptor for a viral or other agent resulting in an enhanced probability of leukemic transformation. A study of the five families of patients with acute myelogenous leukemia studied here suggests that a dominant gene model is operative, in that the presence of a single $109 \mathrm{~d} 6$ epitope is sufficient for determining the susceptibility state.

The differences in results between acute myelogenous leukemia and chronic myelogenous leukemia are of special interest. Evidence suggests that in chronic myelogenous leukemia the target cell for the leukemic transformation is the pluripotent hematopoietic stem cell (52) whereas the transformation in acute myelogenous leukemia apparently occurs in a later cell committed to granulocyte/monocyte differentiation (2). Although by cytoenzymatic and morphologic criteria the myeloblasts in these two diseases are indistinguishable, the 109d6 epitope is not increased in frequency in individuals with chronic myelogenous leukemia. This emphasizes the possibility that the acute myelogenous leukemias are a group of neoplasms characterized by involvement of the molecule bearing the $109 \mathrm{~d} 6$ epitope in a common biologic event that is apparently not important in the type of leukemogenesis characteristic of chronic myelogenous leukemia.

\section{Acknowledgments}

The authors express their thanks to Dr. A. Figur, Dr. R. Zalusky, Dr M. Sanders, Dr. M. Greenberg, and Dr. H. Greenberg for their contribution of the patients in this study; to Ms. Joan Feld and Ms. Barbara Schwartz for performing the HLA typing; and to Mrs. Roslyn Berger and Ms. Nancy Rodriguez for their excellent assistance in the preparation of this manuscript. Victor Sloan provided invaluable technical assistance.

This work was supported by United States Public Health Service grant 19411.

\section{References}

1. Bennet, J. M., D. Catovsky, M. T. Daniel, D. A. Flandren, H. R. Galton, H. D. Gralnick, and C. Sultan. 1976. Proposals for the classification of acute leukemia. Br. J. Haematol. 33:451-458.

2. McCulloch, E. A. 1984. The blast cells of acute myeloblastic leukemia. Clin. Haematol. 13:(2)503-515.

3. Lilleyman, J. S., A. M. Potter, A. E. Watmore, P. Cooke, R. J. Sokol, and J. K. Wood. 1978. Chromosomes in acute nonlymphocytic leukemia. Br. J. Haematol. 39:311-316.

4. Foon, K. A., R. W. Schroff, and R. P. Gale. 1982. Surface markers on leukemia and lymphoma cells: recent advances. Blood. 60:1-19.

5. Schlossman, S. F., L. Chess, R. E. Humphries, and J. Strominger. 1976. Distribution of la-like molecules on the surface of normal and leukemic human cells. Proc. Natl. Acad. Sci. USA. 73:1288-1292.

6. Winchester, R. J., G. D. Ross, C. I. Jarowski, C. Y. Wang, J. Halper, and H. Broxmeyer. 1977. Expression of la-like antigen molecules on human granulocytes during early phases of differentiation. Proc. Natl. Acad. Sci. USA. 74:4012-4016.

7. Bernstein, I., R. Andrews, S. Cohen, and B. McMaster. 1982. Normal and malignant human myelocytic and monocytic cells identified by monoclonal antibodies. J. Immunol. 128:876-881.

8. Winchester, R. J., C. Y. Wang, J. Halper, and T. Hoffman. 1976. Studies with B-cell allo and hetero-antisera: parallel reactivity and special properties. Scand. J. Immunol. 5:745-757.

9. Billing, R., R. Rafizadeh, I. Drew, G. Hartman, R. Gale, and P. Terasaki. 1976. Human B lymphocyte antigens expressed by lymphocyte and myelocytic leukemia cells. I. Detection by rabbit antisera. J. Exp. Med. 144:167-178.

10. Dimitriu-Bona, A., R. J. Winchester, I. Szer, M. Reilly, V. Najfeld, and J. Cuttner. 1982. Expression of early or mature monocyte-related antigens on certain acute myeloid leukemias (AML) before and after culture. Clin. Res. 30:512a. (Abstr.)

11. Dimitriu-Bona, A., G. R. Burmester, S. J. Waters, and R. J. Winchester. 1983. Human mononuclear phagocyte differentiation antigens. I. Patterns of antigenic expression on the surface of human monocytes and macrophages as defined by monoclonal antibodies. $J$. Immunol. 130:145-152.

12. Ball, E., and M. Fanger. 1983. The expression of myeloid specific antigens on myeloid leukemia cells, correlations with leukemic subclasses, and implications from normal myeloid differentiation. Blood. 61:446463.

13. Todd, R. F., L. M. Nadler, and S. Schlossman. 1981. Antigens on human monocytes identified by monoclonal antibodies. J. Immunol. 126:1435-1442.

14. Seremetis, S., V. Sloan, J. Cuttner, and R. Winchester. 1985. Phenotype heterogeneity in acute myelogenous leukemia (AML) detected by monoclonal antibodies (Moab). Clin. Res. (Abstr.). 33:550A.

15. Lilly, F., E. A. Boyse, and L. J. Old. 1964. Genetic basis of susceptibility to viral leukemogenesis. Lancet. II:1207-1209.

16. Oliver, R. T. D., A. Pillai, P. T. Konda, and S. D. Lawler. 1977. HLA linked resistance factors and survival in acute myelogenous leukemia. Cancer (Phila.). 39:2337-2341.

17. Daly, P., P. Simon, C. Shiffer, J. Aisner, P. Terasaki, and P. Wiernik. 1979. A study of HLA antigens and haplotypes in a population of Caucasians with acute non-lymphocytic leukemia. Leuk. Res. 3:7582.

18. VonFliedner, V. E., Z. Sultan-Khan, and M. Jeannet. 1980. HLADRw antigens associated with acute leukemia. Tissue Antigens. 16:399404.

19. D’Amaro, J., J. J. vanRood, F. Bach, A. Rimm, and M. Bortin. 1984. HLA-C association with acute leukemia. Lancet. I.1176-1178. 
20. Hurley, C. K., R. C. Giles, G. Nunez, R. DeMars, L. Nadler, R. J. Winchester, P. Stastny, and J. D. Capra. 1984. Molecular localization of human Class II MT2 and MT3 determinants. J. Exp. Med. 160:472493.

21. Hurley, C. K., G. Nunez, R. Winchester, O. Finn, R. Levy, and J. D. Capra. 1982. The human HLA-DR antigens are encoded by multiple $\beta$ chain loci. J. Immunol. 129:2103-2108.

22. Trowsdale, J., J. Lee, J. Carey, F. Grosveld, J. Bodmer, and W. Bodmer. 1983. Sequences related to HLA-DR $\alpha$ chain on human chromosome 6: restriction enzyme polymorphism detected with DC $\alpha$ chain probes. Proc. Natl. Acad. Sci. USA. 80:1972-1976.

23. Auffray, C., A. J. Korman, M. Roux-Dosseto, R. Bono, and J. L. Strominger. 1982. cDNA clone for the heavy chain of the human B cell alloantigen DC1: strong sequence homology to the HLA-DR heavy chain. Proc. Natl. Acad. Sci. USA. 79:6337-6341.

24. Spielman, R. S., J. Lee, W. F. Bodmer, J. G. Bodmer, and J. Trowsdale. 1984. Six HLA-D region $\alpha$-chain genes on human chromosome 6: polymorphisms and associations of $D C \alpha$-related sequences with DR types. Proc. Natl. Acad. Sci. USA. 81:3461-3465.

25. Gorski, J., P. Rollini, E. Long, and B. Mach. 1984. Molecular organization of the HLA-SB region of the human major histocompatibility complex and evidence for the two SB $\beta$-chain genes. Proc. Natl. Acad. Sci. USA. 81:3934-3938.

26. Sorrentino, R., J. Lillie, and J. Strominger. 1985. Two dimensional gel electrophoresis $\mathrm{NH}_{2}$ terminal amino acid sequence and Southern blot analysis. J. Exp. Med. In press.

27. Toguchi, T., G. R. Burmester, A. Nunez-Roldan, P. Gregersen, S. Seremetis, S. Lee, I. S. Szer, C. K. Hurley, and R. J. Winchester. 1984. Evidence for the separate molecular expression of four distinct polymorphic Ia epitopes on cells of DR4 homozygous individuals. Hum. Immunol. 10:69-81.

28. Toguchi, T., G. Burmester, S. Waters, S. Seremetis, P. Gregersen, A. Nunez-Roldan, and R. Winchester. 1984. Aspects of the fine structure of the human Ia system revealed by monoclonal antibodies directed to polymorphic determinants. Disease Markers. 2:85-92.

29. Nunez-Roldan, A., I. Szer, T. Toguchi, J. Cuttner, and R. J. Winchester. 1982. Association of certain Ia allotypes with the occurrence of chronic lymphocytic leukemia: recognition by a monoclonal anti-Ia reagent of a susceptibility determinant not in the DR series. J. Exp. Med. 156:1872-1877.

30. Giles, R. C., G. Nunez, C. K. Hurley, A. Nunez-Roldan, R. Winchester, P. Stastny, and J. D. Capra. 1983. Structural analysis of a human I-A homologue using a monoclonal antibody which recognizes an MB3-like specificity. J. Exp. Med. 157:1461-1470.

31. Seremetis, S. V., J. Cuttner, and R. Winchester. 1984. Association of susceptibility to acute myelogenous leukemia (AML) with a non-DR Ia allodeterminant. Clin. Res. 32:499a.

32. Cuttner, J., S. Seremetis, V. Najfeld, A. Dimitriu-Bona, and R. J. Winchester. 1984. TdT-positive acute leukemia with monocytoid characteristics: cytochemical, cytogenetic, and immunologic findings. Blood. 64:237-243.

33. Kaplow, L. S. 1975. Simplified myeloperoxidase using benzidene dehydrocholoride. Blood. 26:215-222.

34. Yam, L. T., C. Y. Li, and W. H. Crosby. 1971. Cytochemical identification of monocytes and granulocytes. Am. J. Clin. Pathol. 55: 283-287.

35. Yam, L. T., C. Y. Li, and K. W. Lam. 1971. Tartrate-resistant acid phosphatase isoenzyme in the reticular cells of leukemic reticuloendotheliosis. N. Engl. J. Med. 284:357-360.
36. Bollum, F. S. 1979. Terminal deoxynucleotidyl transferase as a hematopoietic cell marker. Blood. 54:1203-1215.

37. Boyum, A. 1968. Isolation of mononuclear cells and granulocytes from human blood. Scand. J. Clin. Lab. Invest. 21:77-89.

38. Ulmer, A. J., and H. D. Flod. 1979. Discontinuing density gradient separation of human mononuclear leukocytes using percoll as gradient medium. J. Immunol. Methods. 30:1-10.

39. Burmester, G. R., D. T. Y. Yu, A. Irani, H. G. Kunkel, and R. J. Winchester. 1981. $\mathrm{Ia}^{+} \mathrm{T}$ cells in synovial fluid and tissues of patients with rheumatoid arthritis. Arthritis Rheum. 24:1370-1376.

40. Hansen, J. A., S. M. Fu, P. Antonelli, M. Kamoun, J. H. Hurley, R. J. Winchester, B. Dupont, and H. G. Kunkel. 1979. B-lymphoid cell lines derived from HLA-D homozygous donors. Immunogenetics. 8:5164.

41. Terasaki, P. I., M. S. Park, D. Bernoco, G. Opelz, and M. R. Mickey. 1980. Overview of the 1980 international histocompatibility workshop. In Histocompatibility Testing 1980. P. I. Terasaki, editor. UCLA Tissue Typing Laboratory, Los Angeles, CA. 1-17.

42. Thompson, G. 1981. A review of theoretical aspects of HLA and disease association. Theor. Popul. Biol. 20:168-208.

43. Waters, S. J., R. Winchester, F. Nagase, C. J. Thorbecke, and C. A. Bona. 1984. Antigen presentation by murine and human cells to a murine $\mathrm{T}$ cell hybridoma: demonstration of a restriction element associated with an MHC Class II determinant(s) shared by both species. Proc. Natl. Acad. Sci. 81:7559-7563.

44. Goyert, S. M., and J. Silver. 1983. Further characterization of HLA-DS molecules: implications for studies assessing the role of human Ia molecules in cell interactions and disease susceptibility. Proc. Natl. Acad. Sci. USA. 80:5719-5723.

45. Winchester, R. J. 1976. Techniques of surface immunofluorescence applied to the analysis of the lymphocyte. In Methods of Cellular Immunity. B. Bloom and J. David, editors. Academic Press, New York. $171-186$.

46. Navarette, L., L. Fainboim, H. Festenstein, A. Lister, J. Amess, and M. Greaves. 1981. Selective expression of HLA-DR and HLA-MB antigens on acute leukemia cells. In Leukemia Markers. W. Knapp, editor. Academic Press, New York. 65-68.

47. Falkenburg, J. H. F., J. Jansen, N. Vaart-Duinkerken, W. F. J. Veenhot, J. Blotkamp, H. M. Croselink, J. Parlevliet, and J. J. van Rood. 1984. Polymorphic and monomorphic HLA-DR determinants on hematopoietic progenitor cells. Blood. 5:1125-1132.

48. Faille, A., and D. Charron. 1983. MHC Class II antigens: molecular defect or differentiation marker. Blood. 62:5(Suppl. 1)169a.

49. Symington, F. W., M. Braun, S. Brown, S. Hakamori, and B. Torok-Storb. 1984. Molecular and functional comparisons of DR-antigens expressed by autologous erythroid and B lymphoblastoid cells. Blood. 64(Suppl. 1):98a.

50. Gonwa, T. A., L. J. Picker, H. V. Raff, S. M. Goyert, J. Silver, and J. D. Stobo. 1983. Antigen-presenting capabilities of human monocytes correlate with their expression of HLA-DS, an Ia determinant distinct from HLA-DR. J. Immunol. 130:706-711.

51. Nunez, G., R. C. Giles, E. J. Ball, C. K. Hurley, J. D. Capra, and P. Stastny. 1984. Expression of HLA-DR, MB, MT, and SB antigens on human mononuclear cells: identification of two phenotypically distinct monocyte populations. J. Immunol. 133:1300-1306.

52. Martin, P. J., V. Najfeld, and P. J. Fialkow. 1982. B-lymphoid involvement in chronic myelogenous leukemia: implications for the pathogenesis of the disease. Cancer Genet. Cytogenet. 6:359-368. 